\title{
Primum Non Nocere and the Quality of Evidence: Rethinking the Ethics of Screening
}

\author{
Robert M. Ewart, $M D$
}

Background: Screening is different from investigation, and these differences have important implications in the assessment of screening programs.

Metbods: I review the differences between screening and investigation and the implications of these differences derived from a consideration of the four ethical principles of beneficence, nonmaleficence, autonomy, and distributive justice.

Results: Because most of the harms of screening fall on the healthy and because screening is initiated by physicians, nonmaleficence takes ethical precedence over beneficence. Issues related to cost and consent are also approached differently in screening compared with investigation, and both take on greater ethical importance. I contend further that these ethical implications require that screening programs be backed up by better evidence than is the usual case for investigative medicine. I suggest an outline for the appropriate assessment of screening programs and for the ethical responsibilities of those involved in screening.

Conclusions: Many current medical screening practices are not concordant with our ethical principles and should be reassessed. (J Am Board Fam Pract 2000;13:188-96.)

Many current medical screening practices are inconsistent with the ethical principles underlying medical care and are unsupported by acceptable evidence. These practices could be regarded, therefore, as unethical. Recommendations supporting screening programs put physicians in the unenviable position of practicing according to the current standard of care but in an unethical manner or practicing ethically but exposing themselves to professional and legal criticism. This article explores the differences between screening and investigation and the ethical implications of these differences. Whereas some of these topics have been discussed individually by others, there has been no effort to examine the topic as a whole, although there have been calls for such an examination. ${ }^{1-3}$

\section{What is Screening?}

Screening is looking for a disease in those not suspected (except on probabilistic grounds) of hav-

Submitted, revised, 31 August 1999.

From the Department of Family \& Community Medicine, Southern Illinois University School of Medicine, Springfield. Address reprint requests to Robert $M$. Ewart, MD, Department of Family \& Community Medicine, SIU Center for Family Medicine, 520 North 4th St, Springfield, IL 62702-5238. ing it. Screening is different from investigation, in which tests are ordered after disease is suspected. Although screening can be done under many different circumstances, this article considers only the situation of screening competent, uncoerced adults for their own benefit.

There is a distinction between screening tests and screening programs. A screening test is the initial test done to find a condition. A screening program, however, is the screening test (eg, a mammogram), follow-up tests done to confirm the initial test (breast biopsy), and treatment given for abnormal findings (surgery, radiation, chemotherapy). A program could, minimally, consist of a test and telling the patient the result (which might be reassuring and, therefore, beneficial). Screening tests by themselves have no benefit, but they always have some potential for harm, which could on occasion be serious. ${ }^{4}$ It is the screening programs that ultimately are beneficial or harmful and that, therefore, form the appropriate unit of analysis.

The commonly listed criteria necessary for a screening program are as follows: ${ }^{5}$

1. The natural history of the disease should be reasonably well understood. 
2. The burden of suffering from the disease must be high enough to justify screening.

3. The screening test must be reasonably sensitive and specific.

4. The disease must be treatable.

5. Treatment given earlier in the course of the disease must produce a better outcome than treatment given late in the course of the disease.

6. Patients will comply with the offered testing and treatment

7. Resources to run the program must be available.

8. The costs of the program must justify the benefits.

Many authors have expressed agreement with these criteria, with some adding a discussion of selected ethical aspects. ${ }^{6}$ Others have further implied that there is no ethical requirement for physicians to follow recommendations that are not based on these criteria. ${ }^{7,8}$

These recommendations are for the most part technical, and although meeting technical conditions is necessary before a screening program is begun, it is not sufficient. Recommendations about screening should also be analyzed from an ethical standpoint.

\section{Point of View: Public vs Individual Health}

Historically, screening has been associated with public health, for example, screening for infectious diseases for quarantine or screening military recruits for fitness to fight. ${ }^{2}$ At least partly as a consequence of this point of view, advocates of screening have tended to adopt a utilitarian approach, the greatest good for the greatest number. ${ }^{9}$ In overly simplistic terms, this strategy adds the benefits, subtracts the harms (or costs), and if the result is positive, recommends proceeding.

In 1981 Rose $^{10}$ was one of the first to comment on some of the difficulties that can arise from this approach, referring to the "prevention paradox - $a$ measure that brings large benefits to the community offers little to each participating individual." He went on to point out that if "a preventive measure exposes many people to a small risk, then the harm it does may readily ... outweigh the benefits, since these are received by relatively few." More recently Stewart-Brown and Farmer ${ }^{11}$ have said:

Screening programmes affect a large number of people relative to the number who benefit. A small adverse effect of screening on quality of life, health promoting behaviour, or individuals' capacity to care for themselves could have an impact on the public health which outweighs any gain to be achieved by screening.

In the present analysis I reject a simplistic utilitarian approach to the ethical problems of screening and move toward developing an alternative. My point of view will be, for the most part, fixed on the individual. This view is not to deny the public health implications of screening, but merely to point out that man has no general ethical obligation to be healthy, although a person might have obligations to others that involve his or her health, and that person does have an obligation to not affect others with his or her own ill health (including the costs of care for that ill health).

\section{How Is Screening Different From Investigation?}

Screening is different from investigation that is done on those thought to be sick. For example, if a 60 -year-old woman comes into the office with a new, hard lump in her breast, a mammogram might be ordered to investigate this lump. The same woman might, however, have been invited to come in for a checkup, and a mammogram might then be arranged to screen her for breast cancer even in the absence of complaints or findings on physical examination.

This distinction is based on the likelihood of disease. Everyone has some tiny chance of having most diseases. Investigations are done on those thought to have a high preexisting probability of disease, whereas screening is done on those with a low (usually very low) preexisting probability. This distinction can often be modified to mean not "probability of having disease" but "probability of benefitting from treatment." Most 95-year-old men have prostate cancer, but few of them will benefit from treatment. ${ }^{12}$ Dr. Heidi Malm (letter, 1996) has pointed out that this distinction implies that patients who are investigated "have greater room for benefit than ... [those] screened." Patients who have symptoms have the potential of finding, through investigation, that they are not ill; patients who are screened cannot benefit in this way "except for the trivial benefit of knowing one does not have a disease which one had no reason to believe one had in the first place." 
The second difference between screening and investigation relates to who initiates the action. In the usual course of medical care, patients come to physicians for advice; with screening, physicians go to the patient and recommend tests, although this recommendation might be made indirectly.

A third difference is that screening programs are usually evaluated with respect to their effect on the health of a population rather than on the individuals in the population. ${ }^{13}$ When a physician removes someone's gall bladder, the benefit and harm to that person are known to at least some degree. If a physician orders a screening mammogram, the harm will for the most part be known, but the benefit can never be known except statistically. For instance, I know that symptomatic gall bladder disease tends to continue to cause symptoms and that taking out the gall bladder will usually relieve these symptoms. I have, however, only statistical information about the natural history of most cancers, and I cannot ever know whether removing a particular cancer 6 months earlier helped a particular person. There are numerous exceptions to this general rule, mostly involving screening for curable infectious diseases and congenital conditions.

A fourth difference between screening and investigation is that with screening, the costs and harms are immediate, while the benefits are often considerably delayed. For example, a major purpose of screening for and treating high blood pressure is to prevent stroke. Yet most people with high blood pressure will never have a stroke, and patients in their $40 \mathrm{~s}$ will often need to take medication for 20 to 40 years to prevent stroke. This distinction between screening and investigation is not absolute. It is reasonable to suppose that not all patients who have symptoms benefit from the resulting investigations and treatment and that the benefits could be considerably delayed. This course of events is, however, the usual in screening, whereas it is unusual in investigation.

These four distinctions argue for a dichotomous approach to screening vs investigation. In practice, this distinction is not so clearcut. The two exist on a continuum, with screening at one end and investigation at the other; and many of the arguments presented in this article could be applied equally well to the treatment of asymptomatic conditions in otherwise healthy people (eg, giving female sex hormones routinely to postmenopausal women).

\section{What Are the Ethical Implications of These} Differences?

It is generally accepted (and will not be argued further here) that there is a duty to respect four ethical principles in medical decision making. These principles are beneficence, nonmaleficence, autonomy, and justice. ${ }^{14}$

\section{Harms and Benefits}

All screening programs can cause harm. ${ }^{15,16}$ The doctrine of primum non nocere ${ }^{17}$ (first, do no harm) tells physicians that their first ethical consideration should be the potential harm of intervention, and in balancing benefits and harms, to attach more ethical weight to the injunction of nonmaleficence than to that of beneficence. ${ }^{18}$ I do not mean to imply that the duty of nonmaleficence is absolute or that it invariably takes precedence over other ethical responsibilities or even that it invariably takes precedence over beneficence. I am instead arguing here that in most situations physicians have a stronger obligation not to harm people than to help them. I will develop below the specific argument that, in screening, nonmaleficence almost always takes precedence over beneficence.

In the end a patient can be both benefitted and harmed by tests and treatments. When beginning a course of testing and treatment (whether screening or investigation), physicians can know only the statistical likelihood of disease and its various possible outcomes. Given a continuum in the preexisting probability of disease (and of benefitting from treatment), there is an equivalent continuum in the probability of who will be harmed-the healthy or the sick. If a person probably has a disease, then any harm that comes from investigation will fall on someone who is already ill. If, at the other end of the continuum, a person almost certainly does not have a disease, then any harm of screening will fall on someone who was previously healthy. Because the healthy have more to lose than the sick, harming the healthy is, all other things being equal, worse than harming the sick. Alternatively, if a person probably does not have a disease (or would not benefit from finding the disease), a first and most important obligation is to not cause harm by looking for it, and only then does the physician have an obligation to help.

I am not arguing here the more ethically suspicious position that those with less to gain have a 
lower entitlement to health care compared with those with more to gain. I am arguing that those with more to lose have the potential to suffer more harm from intervention and that the potential for harm should therefore be given increased ethical weight.

A second issue in the assessment of the balance between harms and benefits involves who initiates the action. It seems obvious that the person initiating an action has a greater responsibility for the consequences compared with a person responding to the action. When physicians invite patients to come for screening, the responsibility not to harm them increases, and the ethical weight attached to harming them also increases.

The implication of the above is that harm and benefit should be assessed separately and given separate ethical weights, and physicians should proceed only if the utilitarian calculus is then still positive. By doing so, however, simple utilitarianism is effectively gutted as a guiding ethical theory.

To put it in another way, when assessing a screening test, showing that a test is beneficial or reduces disease-specific or overall mortality does not imply that the test is not harmful or that it should automatically be performed.

There are several reasons why this approach has not been accepted historically. The first is probably that screening tests have often been seen to exist in isolation, not as part of screening programs. Because the tests themselves often have few and trivial harms, it has been commonly accepted that even minimal benefit will always outweigh these harms; therefore, a separate assessment is not necessary. The second reason is that, as noted above, screening has often been accepted as part of public health, and public health physicians commonly adopt some variation of utilitarianism in their assessments. This approach, in turn, reinforces an attitude of looking only at the final result rather than the component parts. This perspective is strengthened by the design of randomized, controlled trials, which tend to have a single main outcome measure (although one should note that many, if not most, screening recommendations are not backed up by the results of any well-designed trials.) The third reason is more psychologic: medicine has come to be viewed as a battle against disease. This attitude is reflected in slogans -"The War Against Cancer"-and in simple things, such as obituaries - "he succumbed after a long fight with cancer." It is accepted in war that there will be casualties and the innocent will suffer. This is the price that must be paid for victory. One is asked to count, not the cost, but only the victory, and remember the victims as heroes of the struggle.

\section{Autonomy (Self-Determination)}

Faden et $\mathbf{l}^{19}$ have argued strongly for the prima facie primacy of respect for autonomy in medical decision making as opposed to the historical paternalistic, beneficence-oriented model. Autonomy implies in turn that informed consent holds a central place in our assessment of the ethics of medical interventions. Gillon ${ }^{20,21}$ has taken a somewhat less demanding position arguing for the importance, but not necessarily the primacy, of autonomy.

Whichever of these approaches physicians take, issues surrounding consent change when they move from investigation to screening. There are two reasons for this change. First, whereas the ideal of completely informed consent is difficult to obtain, most reasonable persons understand that there is some risk to the investigations and treatments that are undertaken in the care of the sick. There is an implied risk in all medical encounters, and although consent should be substantially autonomous, it does not need to be completely so. ${ }^{19(\mathrm{pp} 237-241)} \mathrm{My}$ experience as a family physician has been that most reasonable persons do not understand (or understand much less well) that screening tests or programs can harm them (apart from the often trivial harm of the tests themselves); as a consequence, they need to be more informed by giving them both more detailed information (the process of consent) and by paying more attention to the information being understood (the outcome of consent). Further, many do not seem to understand the implications of a screening test being only the first step in a screening program. Consent for the initial screening test, therefore, should include at least some minimal discussion of the risks and benefits of the follow-up tests and treatments. ${ }^{22}$

I am not arguing that every person screened should be given detailed information on every possible outcome of screening. Obviously, judgment is needed regarding the information provided. I am, however, arguing that patients should be aware that they are entering a program with some associated risks and should be given clear and appropriate information about the nature and likelihood of these risks (as well as the benefits). 
A further point concerning the issue of consent is that screening is done by invitation. As noted above, patients have a stronger right to not be harmed by tests and treatments that they did not ask for in the first place. This right imposes a greater burden for consent than that which exists when the patient requests care.

\section{Justice}

Distributive justice refers to the problem of ensuring an equitable distribution of benefits given the constraints of limited resources. ${ }^{23,24}$ Or, as Drummond and Mooney ${ }^{25}$ have put it, "There are not and never will be enough resources to enable the community to pursue all desirable objectives. If this notion of scarcity of resources is accepted, then the logic of comparing the costs and benefits to the community of alternative actions has much appeal." Screening programs must take their place in the ongoing debate on the fair distribution of resources. Screening is, however, different from investigation because it tends to have high up-front costs with delayed benefits, and much of the cost is borne by those who will never benefit.

Accordingly, at least in insurance-based systems of payment, an ethical conflict will often result between the right of individuals to beneficial care and the right of society to determine spending priorities. This conflict is real and admits to no general resolution. On the one hand, the one who pays the piper calls the tune. On the other, everyone has a right to dance to his own music. I favor a double-veto system in which each person has a right to refuse screening even if it is beneficial to society (arguing from autonomy), and society has a right to refuse to pay for screening programs on the grounds of excessive cost (or excessive harms) even if they benefit some members of society (arguing from distributive justice).

My plea is that these issues be brought out to face the light of day so they can be properly discussed and analyzed. It is happening to some extent in American health maintenance organizations, where there is an explicit attempt to ensure equitable distribution of resources to the membership. Crisp et $\mathrm{al}^{26}$ and $\mathrm{New}^{27}$ have discussed some of these issues in the context of the British National Health Service.

Problems in slicing pies can always be solved by making the pie bigger. That is, if screening programs are expensive, the public can simply elect to spend more money. This choice, of course, simply moves issues of distributive justice to a higher level; what is the public willing to give up to have better health?

\section{Screening and the Quality of Evidence}

As noted above, one difference between screening and investigation is in who initiates the procedure-the physician or the patient. The ethical implication relates to the quality and quantity of the evidence that a physician must have before making a recommendation.

In the usual practice of medicine, the physician's evidence should be pretty good. When a patient seeks advice, physicians have an obligation to do their best with the evidence at hand. A physician's assessment of the benefits and harms is a best educated guess, and the weighing of this balance is correspondingly inexact. In screening, both the quality and quantity of the evidence must exceed this standard. Harming someone who has not asked for help is worse than harming someone who has. Patients who want medical help accept that occasionally tests and treatments will cause harm. This implied contract exists to a much lesser degree when the patient has been invited for screening tests. The invitation implies that physicians have an obligation to obtain better evidence regarding the harms and benefits than they do in investigative care.

A good analogy is the evidence necessary in court. In a civil court, the evidence need only be on the balance of probabilities, while in criminal court it must be beyond any reasonable doubt. Evidence in routine medical care is like that in civil law: it will probably help. With screening, the situation is much more like that in criminal law; and the benefits and harms must be known beyond any reasonable doubt.

This viewpoint is supported by Cochrane and Holland (quoted in $\mathrm{McCormick}^{3}$ ):

We believe that there is an ethical difference between everyday medical practice and screening. If a patient asks a medical practitioner for help, the doctor does the best he can. He is not responsible for defects in medical knowledge. If, however, the practitioner initiates screening procedures he is in a very different situation. He should, in our view, have conclusive evidence that screening can alter the natural his- 
tory of disease in a significant proportion of those screened.

Miller ${ }^{8 \mathrm{p}^{3}}$ has similarly stated that:

The crucial distinction between screening and normal medical diagnosis and care is that the provider of screening initiates the process, not the individual who is the subject of screening. ... When a patient goes to see a physician for diagnosis of and hopefully relief from a symptom, or for treatment of an established condition, the physician is required to exercise his or her skills only to the extent that knowledge is currently available. ... At the very least, therefore, those planning to introduce screening have an ethical responsibility to be able to guarantee an overall benefit to the community. This has to be coupled with the responsibility to minimize by all possible means the harm that could accrue to some participants. These responsibilities imply that if valid evidence is not available from properly conducted research studies ... screening programs should not be offered.

The approach to evidence presented here is considerably more conservative than that advocated by many organizations. For example, both the Canadian Task Force on the Periodic Health Examination $^{28}$ and the US Preventive Services Task Force ${ }^{29}$ allow for fairly low-quality evidence to justify screening under some circumstances. I think this approach is incorrect. As a corollary, it would seem the organizations that make recommendations for screening based on no, or almost no, good evidence (for example, the American Cancer Society recommendation for screening for prostate cancer using prostate-specific antigen $[\mathrm{PSA}]^{12}$ ) are acting in a way that can only be described as unethical.

\section{What Is Good Evidence?}

Having said that good evidence is necessary, it behooves me to say more precisely what is meant by good evidence. For the most part, I mean randomized controlled trials (RCTs). Nonrandomized and uncontrolled trials suffer from volunteer bias, ${ }^{30}$ lead-time bias, and sampling interval bias, which make screening appear to be beneficial regardless of whether it actually is. These biases can be avoided by the use of the RCT.
I am not arguing that all screening programs need to be justified by an RCT. I am arguing that RCTs are necessary in all situations in which they are possible, and in situations where RCTs are unnecessary or inappropriate, the next best evidence must be obtained. I am arguing strongly against the position that screening should proceed based on the best available evidence, which might be of fairly low quality and not meet the standards referred to above.

\section{Specific Examples}

I am somewhat reluctant to include specific examples of screening programs that I feel are good or bad, as I do not want to confuse the general argument with the pros and cons of particular programs. With that caveat in mind, the following examples might be considered.

1. PSA screening fails because of a lack of good evidence showing benefit. ${ }^{12}$

2. Advising women to examine their breasts regularly fails because there is evidence that it is ineffective, ${ }^{31}$ and there is no good evidence that it is effective.

3. Stool occult blood screening fails because of prohibitive costs even though the program has well-defined benefits. ${ }^{32,33}$

4. Screening low-risk women for hypercholesterolemia fails on the grounds of excessive costs and harms and unknown benefits. ${ }^{34}$

5. Papanicolaou screening is probably good. ${ }^{35,36}$ Although there are no randomized trials supporting the program, there are sufficient epidemiologic data to continue. The costs are reasonably well understood, and the harms are fairly well understood. Further research could be useful in the areas of harm and consent.

6. Blood pressure screening passes most of the tests, at least as long as treatment is restricted to those at substantial risk. There is good evidence from controlled trials about the benefits, harms, and costs. ${ }^{37}$ An understanding of consent is poor but could be easily rectified.

\section{Conclusions}

To date, for health policy decisions regarding whether screening tests and programs should be offered, mostly technical aspects have been considered: does the program work in the small sense of 
reducing morbidity or mortality from the disease in question? The medical establishment is now in a position to expand the requirements to include an ethical dimension.

1. In screening, in contradistinction to investigation, most of the harm falls on healthy persons, and in this situation particularly, the doctrine of nonmaleficence becomes of prime importance. Harms should be assessed separately from the benefits, and screening should proceed only if the harms are thought to be acceptable.

2. Consent for screening (autonomy) needs to be more informed than is usual in investigative medicine and needs to address not simply the screening test but the screening program. A formal evaluation of the ability to get consent at the population level must be undertaken and must be judged to be acceptable before a screening program is implemented. After implementation, consent must still be obtained on an individual level.

3. Issues of distributive justice must be addressed at both the population and the individual levels before screening recommendations can be made.

4. Because screening is done by invitation, and because it is always possible to get good evidence before screening tests are recommended, the acceptable evidence for screening must be much better than the evidence used for routine care. Evidence for screening for risk factors should include evidence of the effect on the underlying disease as well as general health and well-being.

The analysis presented here differs considerably in its implications from that presented by others. These differences can be approached from several points of view: the government, the expert organization, the insurer, the physician, and the patient.

1. The government has the overall responsibility for laying out the rules of the game with respect to both the general distribution of resources and to the legal rules under which medicine is practiced. These would include rules regarding physicians' general responsibility toward patients and about standards of care. Insurers (both public and private) have the primary responsibility of translating these general rules into decisions about distributive justice at the societal level (ie, in making health policy decisions). It is possible that some programs are simply too expensive to implement in any population even though they have well-defined health benefits.

2. Expert organizations have the responsibility to collect, assess critically, and present the evidence regarding the harms and benefits (to both those found to have disease and those not), the costs, and the procedures and outcomes of getting consent at the population level, but not to make any further recommendations regarding screening.

3. Individual physicians have the ultimate responsibility of recommending screening tests to their patients. They have three responsibilities: to assess critically the evidence presented to them by recommending organizations and insurers, to assess issues of distributive justice that exist at the level of their individual practices, and to insure that informed consent is obtained.

4. Patients have an obligation to assess critically the information they have been given and to make an individual assessment of the balance between harms, benefits, and costs (both individual and social) and to decide whether they wish to be screened.

Expert organizations, insurers, physicians, and patients have a positive ethical obligation to not proceed until the above criteria have been fulfilled and, if they do not do so, they could be regarded as acting in an unethical manner.

An effect of these recommendations is that screening becomes messier. Those involved in screening move from a system of very clean recommendations to a much less tidy, more uncertain, and often inconsistent situation.

\section{Implications for Further Research}

The first implication is that most current recommendations need to go back to the drawing board. Although there is sometimes reasonable information regarding the benefits of screening, the understanding of the harms is limited. Much more debate needs to take place regarding how ethical weight is attached to harming the healthy and how these harms are balanced against benefits. An understanding of the process of getting consent (both at the societal and the individual level) is almost non- 
existent. There is some ability to assess costs, although exactly how to do it remains controversial. $^{38-40}$ Future screening trials should gather information prospectively on harms, costs, and consent as well as benefits. Decisions about distributive justice remain contentious, as evidenced by recent debates about rationing in Oregon ${ }^{41}$ and British fundholding. ${ }^{42}$ Should spending decisions be made rationally, by physicians, by social consensus, or by the squeaky-wheel-gets-the-grease principle? ${ }^{43}$

Further research needs to be undertaken on the process by which screening recommendations move from opinions to guidelines to standards and the implications of this process in the organization of medical care and for legal liability. Currently, influential organizations make recommendations based on incomplete assessment, and physicians feel obliged to follow them because of fear of criticism (both medical and legal). As a result, these recommendations become the standard of care. This outcome is obviously unacceptable (and unethical), and the process by which it happens needs reassessment.

Particular thanks to Dr. Heidi Malm for ideas and criticism. Other colleagues too numerous to mention have provided constructive criticism of earlier drafts of this manuscript. Acknowledgment is also given to the anonymous referees who reviewed earlier drafts.

\section{References}

1. Skrabanek $P$. Why is preventive medicine exempted from ethical constraints? J Med Ethics 1990;16:18790.

2. Horner JS. Medical ethics and the public health. Public Health 1992;106:185-92.

3. McCormick J. Health promotion: the ethical dimension. Lancet 1994;344:390-1.

4. Weil JG, Hawker JI. Positive findings of mammography may lead to suicide. BMJ 1997;314:754-5.

5. Sackett DL, Haynes, RB, Guyatt GH, Tugwell P. Clinical epidemiology: a basic science for clinical medicine. 2nd ed. Boston: Little, Brown; 1991:15470.

6. Mant D, Fowler G. Mass screening: theory and ethics. BMJ 1990;300:916-8.

7. Taplin SH, Mandelson MT. Principles of cancer screening for clinicians. Prim Care 1992;19:513-33.

8. Miller $A B$. The public health aspects of screening: principles and ethical aspects. In: Miller $\mathrm{AB}$, editor. Advances in cancer screening. Boston: Kluwer Academic Publications; 1996:3.
9. Gillon R. Utilitarianism. Br Med J (Clin Res Ed) 1985;290:1411-3.

10. Rose G. Strategy of prevention: lessons from cardiovascular disease. $\mathrm{Br}$ Med J (Clin Res Ed) 1981;282: 1847-51.

11. Stewart-Brown S, Farmer A. Screening could seriously damage your health: decisions to screen must take account of the social and psychological costs. BMJ 1997;314:533-4.

12. Woolf SF. Screening for prostate cancer with prostate-specific antigen. An examination of the evidence. N Engl J Med 1995;333:1401-5.

13. Cribb A, Haran D. The benefits and ethics of screening for breast cancer. Public Health 1991;105:63-7.

14. Gillon R. Medical ethics: four principles plus attention to scope. BMJ 1994;309:184-8.

15. Haynes RB, Sackett DL, Taylor DW, Gibson ES, Johnson AL. Increased absenteeism from work after detection and labeling of hypertensive patients. N Engl J Med 1978;299:741-4.

16. Stoate HG. Can health screening damage your health? J R Coll Gen Pract 1989;39:193-5.

17. Gillon R. "Primum non nocere" and the principle of non-maleficence. $\mathrm{Br}$ Med J (Clin Res Med) 1985; 291:130-1.

18. Gillon $\mathrm{R}$. Beneficence: doing good for others. $\mathrm{Br}$ Med J (Clin Res Med) 1985;291:44-5.

19. Faden RR, Beauchamp TL, King NMP. A history and theory of informed consent. New York: Oxford University Press; 1986.

20. Gillon R. Autonomy and the principle of respect for autonomy. Br Med J (Clin Res Med) 1985;290: 1806-8.

21. Gillon R. Consent. Br Med J (Clin Res Med) 1985; 291:1700-1.

22. Edwards PJ, Hall DM. Screening, ethics, and the law. BMJ 1992;305:267-8.

23. Gillon R. Justice and medical ethics. Br Med J (Clin Res Med) 1985;291:201-2.

24. Gillon R. Justice and allocation of medical resources. Br Med J (Clin Res Med) 1985;291:266-8.

25. Drummond MF, Mooney GH. Essentials of health economics. Part V - Assessing the costs and benefits of treatment alternatives. $\mathrm{Br}$ Med J (Clin Res Med) 1982;285:1561-3.

26. Crisp R, Hope T, Ebbs D. The Ashbury draft policy on ethical use of resources. BMJ 1996;312:1528-31.

27. New $B$. The rationing agenda in the NHS. Rationing Agenda Group. BMJ 1996;312:1593-601.

28. The Canadian guide to clinical preventive health care. Canadian Task Force on the Periodic Health Examination. Ottawa: Canada Communications Group, 1986:xxv-xxxvi.

29. Guide to clinical preventive services: report of the US Preventive Services Task Force. 2nd ed. Baltimore: Williams \& Wilkins; 1996:xxxix-lv, 861-2. 
30. Epstein LH. The direct effects of compliance on health outcome. Health Psychol 1984;3:385-93.

31. Semiglasov VF, Moiseenko VM, Protsenko SA, et al. [Preliminary results of the Russia (St. Petersburg)/ WHO program for the evaluation of the effectiveness of breast self-examination.] Vopr Onkol 1996; 42(4):49-55.

32. Kronborg $\mathrm{O}$, Fenger $\mathrm{C}$, Olsen J, Jørgensen OD, Sondergaard $\mathrm{O}$. Randomised study of screening for colorectal cancer with faecal-occult-blood test. Lancet 1996;348:1467-71.

33. Hardcastle JD, Chamberlain JO, Robinson MH, et al. Randomised controlled trial of faecal-occultblood screening for colorectal cancer. Lancet 1996; 348:1472-7.

34. Downs JR, Clearfield M, Weis S, et al. Primary prevention of acute coronary events with lovastatin in men and women with average cholesterol levels. Results of AFCAPS/TexCAPS. Air Force/Texas Coronary Atherosclerosis Prevention Study. JAMA 1998;279:1615-22.

35. Morris $M$. Preinvasive lesions of the female genital tract. In: Kase N, Weingold AB, Gershenson DM., editors. Principles and practice of clinical gynecology. 2nd ed. New York: Churchill Livingstone, 1990:801-25.

36. Sasieni $P$, Adams J. Effect of screening on cervical cancer mortality in England and Wales: analysis of trends with an age period cohort model. BMJ 1999; 318:1244-5.

37. Collins R, Peto R, MacMahon S, et al. Blood pressure, stroke, and coronary heart disease. Part 2, short-term reductions in blood pressure: overview of randomised drug trials in their epidemiological context. Lancet 1990;335:827-38.

38. Singer $\mathbf{P}$, McKie J, Kuhse H, Richardson J. Double jeopardy and the use of QALYs in health care allocation. J Med Ethics 1995;21:144-50.

39. Harris J. Double jeopardy and the veil of ignorance - a reply. J Med Ethics 1995;21:151-7.

40. Leplège $A$, Hunt $S$. The problem of quality of life in medicine. JAMA 1997;278:47-50.

41. Daniels N. Is the Oregon rationing plan fair? JAMA 1991;265:2232-5.

42. Maynard A, Bloor K. Introducing a market to the United Kingdom's National Health Service. N Engl J Med 1996;344:604-8.

43. Stronks K, Strijbis AM, Wendte JF, GunningSchepers LJ. Who should decide? Qualitative analysis of panel data from public, patients, healthcare professionals, and insurers on priorities in health care. BMJ 1997;315:92-6. 